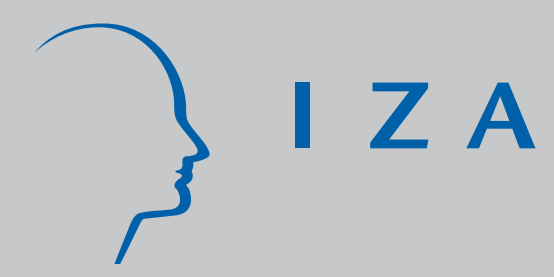

IZADP No. 1480

Cooperative Models in Action:

Simulation of a Nash-Bargaining Model of Household Labor Supply with Taxation

Olivier Bargain

Nicolas Moreau

J anuary 2005 


\title{
Cooperative Models in Action: Simulation of a Nash-Bargaining Model of Household Labor Supply with Taxation
}

\author{
Olivier Bargain \\ IZA Bonn \\ Nicolas Moreau \\ GREMAQ \\ and LIRHE, University of Toulouse 1
Discussion Paper No. 1480
January 2005

\author{
IZA \\ P.O. Box 7240 \\ 53072 Bonn \\ Germany \\ Phone: +49-228-3894-0 \\ Fax: +49-228-3894-180 \\ Email: iza@iza.org
}

\begin{abstract}
Any opinions expressed here are those of the author(s) and not those of the institute. Research disseminated by IZA may include views on policy, but the institute itself takes no institutional policy positions.
\end{abstract}

The Institute for the Study of Labor (IZA) in Bonn is a local and virtual international research center and a place of communication between science, politics and business. IZA is an independent nonprofit company supported by Deutsche Post World Net. The center is associated with the University of Bonn and offers a stimulating research environment through its research networks, research support, and visitors and doctoral programs. IZA engages in (i) original and internationally competitive research in all fields of labor economics, (ii) development of policy concepts, and (iii) dissemination of research results and concepts to the interested public.

IZA Discussion Papers often represent preliminary work and are circulated to encourage discussion. Citation of such a paper should account for its provisional character. A revised version may be available directly from the author. 


\title{
ABSTRACT \\ Cooperative Models in Action: Simulation of a Nash-Bargaining Model of Household Labor Supply with Taxation
}

\begin{abstract}
Several theoretical contributions, starting with McElroy and Horney (1981) and Manser and Brown (1980), have suggested to model household behavior as a Nash-bargaining game. Since then, very few attempts have been made to operationalize cooperative models of household labor supply for policy analysis. In this paper, we implement a Nash-bargaining model with external threat points (divorce) into the microsimulation of tax policy reforms in France. Following the suggestion of McElroy (1990) to achieve identification, we assume that the observation of single individuals can be used to predict outside options. Individual preferences in couples are allowed to display caring between spouses and are simulated in a way which guarantee consistency with the Nash bargaining setting, regularity conditions and observed behaviors. An extensive sensitivity analysis is provided in order to examine the various implications from using the cooperative model for tax policy analysis and the likely role of taxation on intra-household negotiation.
\end{abstract}

JEL Classification: $\quad$ C25, C52, C71, D11, D12, H31, J22

Keywords: collective model, Nash-bargaining model, intrahousehold allocation, household labor supply, tax reform, microsimulation

Corresponding author:

Olivier Bargain

IZA Bonn

P.O. Box 7240

53072 Bonn

Germany

Email: bargain@iza.org 


\section{Introduction}

Over the recent years, the traditional 'unitary' representation of household behavior has been challenged by models accounting for the presence of several decision-makers with possibly specific preferences. Whereas the unitary approach postulates that households maximize a single utility function as if preferences were common or if one member acted as a dictator, 'collective models' (in the broadest sense) solve the multi-utility framework by assuming that a cooperative negotiation is taking place between spouses. ${ }^{1}$ Since the seminal contributions of Manser and Brown (1980) and McElroy and Horney (1981) (MB-MH hereafter), several models specify the nature of the household game, most often as a Nash-bargaining game, while the encompassing collective model of Chiappori (1988a, 1992) postulates only the efficiency of household decisions. This new generation of models is of crucial importance to analyse the intra-household distribution of resources and has raised great hope to understand the complex implications of economic policy within households.

However, as noted in Apps and Rees (1999), the intra-household effects of tax policy have been the subject of very little empirical research. Relying on Chiappori's model, Laisney (2002), Vermeulen (2004) and Bargain and Moreau (2004) are among the rare papers which attempt to empirically characterize the specific role of taxes and transfers on the negotiation rule. Yet the semi-structural nature of the collective model is a drawback insofar as the bargaining process appears only as a reduced form. Then, there is hardly any guidance concerning the factors that could affect negotiation (see Browning and Lechene, 2001) and, in particular, the way taxation could come into play.

Interestingly, the additional structure provided by the Nash-bargaining assumption can alleviate the indeterminacy about the final location on the Pareto frontier and make explicit the likely role of taxes or transfers on intrafamily negotiation, conditionally on particular assumptions about outside options. ${ }^{2}$ This is the path followed in the present paper. We assume that threat points correspond to the divorce situation so that tax-benefit rules for single individuals rather than couples could influence the negotiation within couples. While divorce threats may be too costly to matter in every day negotiation, some types of decisions, including location choices or labor supply, may be seen as strategic and considered in reference to the outside 'single life' situation in a Nash-bargaining framework. It conforms to some wide-spread intuitions regarding the impact of taxes and benefits, e.g. higher benefits for lone mothers increase the outside options of married women with children and the probability of divorce. ${ }^{3}$ It also conforms to

\footnotetext{
${ }^{1}$ See Chiappori and Donni (2004), Lundberg and Pollak (1996), Donni (2000) and Vermeulen (2002) for recent surveys.

${ }^{2}$ Important theoretical contributions elaborate on this point, notably in the case where threat points result from a non-cooperative behavior in the household. See Lundberg and Pollak (1993), Haddad and Kanbur (1994), Konrad and Lommerud (2000) and Chen and Woolley (2001).

${ }^{3}$ For instance, González (2004) uses European cross-country comparisons to suggest that higher levels of benefits imply a higher occurence of single motherhood. Similarly, Rubalcava and Thomas (2000) find that variations in the AFDC (Aid to Families with Dependent Children) across US states directly affect bargaining
} 
the recent estimations of the collective model of labor supply, which incorporate environmental distribution factors related to external outside options and the (re-)marriage market. ${ }^{4}$

The estimation of labor supply in multi-utility models is rare, especially when models account for tax-benefit systems or participation decisions. ${ }^{5}$ In the case of Nash-bargaining models, no closed forms of leisure functions are available, except for highly restrictive functional forms. ${ }^{6}$ It is possible to estimate the Nash product directly using maximum likelihood technique. Barmby (1996) estimates individual preferences simultaneously on single individuals and 'Nash-bargaining couples'. In that case, too, econometric identification still requires the use of simple functional forms. ${ }^{7}$

In this paper, we suggest to rely on simulations to account for nonlinear taxation, participation decisions and general representations of individual preferences. This way, our exercise allows us to study some of the implications of the Nash-bargaining framework within a realistic setting and in relation to concerns for policy analysis. In particular, we analyse the plausible sensitivity of labor supply behaviors to variation in outside options.

We acknowledge the fact that any implementation of the Nash-bargaining model requires cardinalization assumptions. Following the suggestion of McElroy (1991), we use preferences estimated on single individuals to predict outside options and discuss extensively the various transformations that marriage can induce on individual preferences in a neo-classical framework. To cover some of them in the model, we depart from singles' preferences by generating a series of preference regimes for individuals in couples, calibrated to be consistent with observed behaviors and regularity conditions. We naturally ignore which of these regimes come closer to reality but we can perform sensitivity analysis over the whole set of values when assessing the effect of exogenous shocks on outside options. In addition, we do not assume egoistic individuals but account for caring between spouses, in the sense of Becker (1981).

The sensitive analysis considers the effects of homogenous variations in spouses' outside options on labor supply and divorce. These results are then compared to the effect of a realistic tax-benefit reform, inducing a pure distributive effect via the outside options. More precisely, we study several levels of increase in child benefits for lone parents and their subsequent impact

power of women within marriage and subsequently household decisions on consumption and time allocation.

${ }^{4}$ Chiappori et al. (2002) introduce divorce laws and the sex ratio, for instance. They note that their result rejects an important restriction of models in which no environmental distribution factors influence behavior, in particular unitary models and the "separate spheres" model (Lundberg and Pollak, 1993) which assumes that the only threat point is an uncooperative marriage.

${ }^{5}$ In the collective model literature, exceptions are Barmby and Smith (2001) and Barmby (1994) in a setting with neither participation decisions nor taxation, Blundell et al. (2001) who account for participation decisions, Moreau and Donni (2002) and Vermeulen (2004) who both account for nonlinear taxation.

${ }^{6}$ Labor supplies stemming from the Nash program cannot be retrieved analytically, except for unlikely welfare indices such as $W^{i}\left(c, h^{i}\right)=a_{1}^{i} c+a_{2}^{i}\left(T-h^{i}\right)$. In the case of egoistic partners with Stone-Geary preferences, for instance, Barmby (1996) proves that it is not possible to derive the corresponding labor supplies.

${ }^{7}$ Barmby (1996) uses the same Cobb-Douglas specification for all individuals and assumes this way that individuals in couples are egoistic and have the same preferences as singles. The same assumption is used in Barmby and Smith (2001) and Barmby (1994). 
on the reservation utility of women in couples, assuming that women systematically keep the children after divorce.

The outline of the paper is as follows. Section 2 presents the Nash-bargaining setting and the identification hypothesis. In section 3, we describe the implementation of the model. Section 4 deals with the analysis of the potential impacts of exogenous variations in outside options on individual labor supply. In Section 5, a tax-benefit reform is simulated and we assess its impact on outside options. Section 6 concludes the text.

\section{Simulation of a Nash-bargaining model of labor supply with discrete choices and taxation}

\subsection{A cooperative setting}

Following MB-MH, the model postulates two individuals, $f$ and $m$, who, if they live as a couple (i.e. married or cohabiting), jointly allocate resources according to the solution to a two-person, cooperative Nash-bargaining model. As is well-known, the particular allocation reached is likely to depend on what happens in the event of disagreement. In this paper, we define the threat points of $f$ and $m$ as the maximum utility she (he) can obtain if single. For MB-MH, this level of 'reservation utility' below which marriage/cooperation breaks can be interpreted as the utility when divorced.

To be more specific, let $U_{0}^{i}$ be member $i$ 's level of utility when single, $i=f, m$. Let $U^{i}$ and $W^{i}$ respectively denote member $i$ 's egoistic sub-utility and welfare index when she (he) lives in a couple; both terms are explained below. Let $c$ denote total household consumption, $h^{i}$ member $i$ 's labor supply and $w_{i}$ member $i$ 's wage rate. We model the household's decision as the solution to the following problem:

$$
\begin{array}{rr}
\underset{c, h_{f}, h_{m}}{\max } & {\left[W^{f}\left(c, h^{f}, h^{m}\right)-U_{0}^{f}\right]\left[W^{m}\left(c, h^{f}, h^{m}\right)-U_{0}^{m}\right]} \\
\text { s.t. } & c=g\left(w_{f} h^{f}, w_{m} h^{m}, y_{0}, \zeta\right) .
\end{array}
$$

Total consumption, equivalent to total disposable income in such a static framework, depends not only on individual earnings but also on nonlabor income $y_{0}$, on household socio-demographic characteristics $\zeta$ (that can influence the computation of the taxes paid or the benefits received) and on the tax-benefit system symbolized by function $g$.

\section{$2.2 \quad$ Specification of preferences}

A general representation of individual $i$ 's preferences when single is the quadratic form:

$$
U_{0}^{i}\left(c^{i}, h^{i}\right)=\alpha_{10}^{i} c^{i}+\alpha_{20}^{i}\left(T-h^{i}\right)+\alpha_{12}^{i} c^{i}\left(T-h^{i}\right)+\alpha_{11}^{i}\left(c^{i}\right)^{2}+\alpha_{22}^{i}\left(T-h^{i}\right)^{2},
$$

where $c^{i}$ represents individual consumption and $T$ total time endowment. This specification turns out to be flexible enough to be considered as a second order approximation to any type of 
utility (see Stern, 1986 and Ransom, 1987). Some parameters are agent-specific since observed demographic heterogeneity and unobserved heterogeneity can be taken into account.

Primarily, marriage is likely to change preferences. Love, caring, etc., are aspects which imply a transformation of preferences as described in Manser and Brown (1980). Compared to single life, it is possible that married people face (i) a different overall level of welfare for a given consumption bundle (e.g. people are simply 'happier' because they are married), (ii) a different marginal tax rate of substitution between different goods and in particular between leisure and consumption (i.e., tastes change after marriage), (iii) a redefinition of choice variables (e.g. leisure can now be private or shared), (iv) a change of welfare specifically due to the presence of the partner (altruism, externalities). Naturally, this general statement applies to all types of modelling of household behaviors. Yet the multi-utility framework helps drawing attention on the difficulties around the cardinalization issue.

In the present exercise, we do not strive to cover all the transformations implied by marriage but suggest a setting which attempts to be as general as possible within the usual Nashbargaining framework. On the one hand, we follow McElroy (1990) and assume that $\alpha$ parameters can be estimated on samples of single individuals to realistically predict threat points for individuals in couples. On the other hand, we allow married life to have two effects on individual welfare, compared to single life. ${ }^{8}$ Firstly, it may change individual preference parameters to give, for $i=f, m$ :

$$
U^{i}\left(c, h^{i}\right)=\beta_{10}^{i} c+\beta_{20}^{i}\left(T-h^{i}\right)+\beta_{12}^{i} c\left(T-h^{i}\right)+\beta_{11}^{i}(c)^{2}+\beta_{22}^{i}\left(T-h^{i}\right)^{2},
$$

where $\underline{\beta}^{i}=\underline{\alpha}^{i}+\underline{\Delta}^{i}$. The reference situation is single life $-\alpha$ parameters - from which we depart by drawing a series of $\Delta s$ which assure that preference regimes of 'Nash-bargaining couples' are consistent with observed behaviors, in a way described thereafter. Note that varying the values in vector $\underline{\beta}$ around those of vector $\underline{\alpha}$ provides a way to conduct the sensitivity analysis referred to in points (i) and (ii). Secondly, we assume that total individual welfare when married is given by:

$$
W^{i}=U^{i}\left(c, h^{i}\right)+k^{i} U^{j}\left(c, h^{j}\right),
$$

where $k^{i} \in[0,1]$, with $i \neq j .{ }^{9}$ Each member is supposed to regard a welfare index that depends on both her (his) own egoistic utility and her (his) companion's. In other words, each cares about the other's utility, not the partner's consumption choices per se. Preferences of this type are often called 'caring preferences' in the sense of Becker (1981). Hereafter, we will refer to $k^{i}$ as member $i$ 's degree of caring. This way, we account to some extent for altruistic behaviors mentioned in point (iv) above. ${ }^{10}$ Naturally, points (iii) and (iv) would require to account for all types of externalities and in particular for possible complementarity in leisure.

\footnotetext{
${ }^{8}$ In the following, the term 'married' concerns married couples as well as cohabiting couples.

${ }^{9}$ We assume that the functions $U_{0}^{i}, U^{i}$ and $W^{i}$ are all strictly quasi-concave and strictly monotonic in their arguments.

${ }^{10}$ We further assume that the degree of caring $k^{i}$ does not depend neither on the preference parameters $\underline{\beta}^{i}$ nor on current or past choices of each partner's labor supply.
} 
Notice that Chen and Woolley (2001) fully explore the theoretical implication of the Nashbargaining model using a similar specification in the case of internal threat points, modeled as non-cooperative equilibria. Notice also that in the recent literature on collective models, encompassing any specific cooperative solution, the derivation of testable restrictions has most often resorted to a two-stage budgeting interpretation which requires egoistic or caring preferences. Barmby (1996) and Del Boca and Flinn (2004) assume egoistic preferences for individuals in couples. Note also that the utilities depend on total consumption. This assumption, also made by Ashworth and Ulph (1981), Barmby $(1994,1996)$ or Kooreman and Kapteyn (1990), is chosen for practical purposes as we cannot retrieve the level of individual private consumptions from the sole observation of total consumption. ${ }^{11}$

\subsection{Cardinalization assumptions}

The Nash solution requires a cardinal representation of preferences, i.e. it is not invariant to some arbitrary monotonic transformation of utilities, threat points or both. One may have to arbitrarily choose a particular cardinal representation, from the infinity compatible with observed labor supply, and the conclusion then crucially depends on this choice. The main concern is to compare the welfare of individuals in couples with their reservation utility in the case of divorce. We have previously described the set of cardinalization assumptions for both individual welfare indices when married and for outside options $\left(i . e \underline{\beta}^{i}=\underline{\alpha}^{i}+\underline{\Delta}^{i}\right)$. Notice, however, that the choice of caring preferences also implies a necessary comparability between spouses' sub-utilities. To be generally consistent on those accounts, then, we must ensure that each type of cardinalization is close enough for both wives and husbands. For this purpose, we impose the following normalization:

$$
\begin{array}{lll}
\beta_{10}^{f}+\beta_{20}^{f}+\beta_{12}^{f}+\beta_{11}^{f}+\beta_{22}^{f}= & \beta_{10}^{m}+\beta_{20}^{m}+\beta_{12}^{m}+\beta_{11}^{m}+\beta_{22}^{m} & \\
\alpha_{10}^{i}+\alpha_{20}^{i}+\alpha_{12}^{i}+\alpha_{11}^{i}+\alpha_{22}^{i} & =1 & i=f, m .
\end{array}
$$

The $\beta s$ are not forced to sum up to unity in (4) since marriage may lead to larger levels of welfare as argued in point (i). ${ }^{12}$

\footnotetext{
${ }^{11}$ This would not be a problem, as the allocation rule is easily derivable from first order conditions (see Bargain and Moreau, 2004, in the case of a collective model). As mentioned in the introduction, however, it is not possible to derive marshallian demand functions in the case of a Nash framework, except for very restrictive functional forms.

${ }^{12}$ In addition to the cardinalization issue, a debate has arisen concerning the empirical content of the Nash solution, following MB-MH papers. See McElroy (1990), McElroy and Horney (1990) and Chiappori (1988b, 1991). In a recent paper, Chiappori and Donni (2003) have proved that once threat points and utility functions satisfy a specific property of separability (a double exclusion condition), the Nash solution generates a set of specific restrictions on observed behaviors.
} 


\subsection{Economic gains to marriage}

In addition to the gains related to preferences as described above, there are clear economic gains to mary. Well-known types of gain relate to taxation, economies of scale and division of labor in the household.

Firstly, the splitting system in France (extended to the presence of children) allows large tax reductions for married couples, all the larger so as the spouses' earnings differ. For the present exercise, we use the microsimulation model SYSIFF98, described in Bargain and Terraz (2003), which covers the complete French tax and benefit rules so that differences in the tax treatment of couples and single individuals are accounted for in a truthful way.

Secondly, the hypothesis of pure public consumption implies large economies of scale, probably too large however. The same hypothesis is made implicitly in all the literature using equivalence scales. Ideally, one should consider both public goods (leading to economies of scale) and private goods in the household. This goes far beyond the present exercise related to labor supply. ${ }^{13}$

Thirdly, the traditional view on marriage argues that households benefit from a division of labor with one spouse specializing in market production while the other specializes in domestic production. This view has changed in the recent decades but household production is an important aspect too often neglected. Unfortunately, we follow the bulk of the literature on that account, since the incorporation of domestic production still poses theoretical problems in the collective setting and would require many more assumptions here. ${ }^{14}$

\subsection{Discrete choices and the tax-benefit system}

To account for both choice of hours and participation decisions, we opt for a discrete choice model in which the set of possible working hours reflects the actual distribution of hours for France, as shown in Figure ?? in the Appendices. Labor supply in France is indeed concentrated on a small number of working hours due to demand-side and institutional rigidities. The comparison with the United-States, for instance, is striking. In the PSID, year 1990, and using the same selection as done here for couples, we find that there are no obvious concentrations in the distribution of hours, apart from the mode between 38 and 40 weekly hours. This spike itself concerns only $26.5 \%$ (resp. 17.4\%) of US men (resp. women) in couples compared to $52.6 \%$ (resp. $37.7 \%$ ) of the French men (resp. women) in couple.

The discretization thus consists of $h^{f}=0,20,30,39,45$ hours per week and of $h^{m}=0,20$,

\footnotetext{
${ }^{13}$ See Lewbel et al. (2003) for an innovative construction of equivalence scales building on a collective model of consumption.

${ }^{14}$ However, recent and important findings from Donni (2004) show that (i) simple functional forms which are consistent with the traditional collective model of labor supply can sometimes be compatible with more sophisticated models incorporating domestic production; (ii) if the domestic good is marketable, these models can be tested and partially identified using traditional household surveys (i.e. without resort to time allocation surveys).
} 
30, 39, 45, 50, 55 hours per week. ${ }^{15}$ For each household and for each combination $\left(h^{f}, h^{m}\right)$, we compute the function $g$ in (1) using the microsimulation program and obtain the corresponding level of disposable income $c$. Problem (1) then boils down to the choice of the optimal labor supply combination.

\subsection{Children and childcare costs}

A realistic approach requires the impact of the demographic structure of the household to be modelled in several ways (see Browning, 1992). As often in the related literature, children have no decision-making power in the household and their preferences are internalized in those of the parents whereas expenditures on children are included in total household consumption. For households with small children, childcare represents a substantial potential cost of work. Therefore, we deduct from total consumption $c$ a cost of childcare depending on the number and age of the children in the household, according to published related information. ${ }^{16}$ Still, allowing for expenditures on children and time for childcare to be decision variables is an important subject of further research.

\section{Implementation of the model}

\subsection{Predicted threat points}

\subsubsection{Estimations on single individuals}

We need to obtain information on how individuals in a supposedly cooperative couple would act as single individuals. For this purpose, we predict threat points using estimations on subsamples of single men and women. Naturally, if the underlying interpretation is really divorce, then samples of divorced men and women would be better; unfortunately, we are restricted by sample size on this account.

Also, if the selection into marital status is not random, estimation on singles is biased unless the so-called selectivity bias is accounted for. However, it is not clear what could identify the marital relation rules. Following, among others, Barmby (1994), Chiappori et al. (2002), Fortin and Lacroix (1997) or Lewbell et al. (2003), we do not address this question in this paper. It certainly deserves further attention.

The technique used consists of directly estimating the parameters of vector $\underline{\alpha}^{i}$ in expression (2). This is done simply by direct estimation of the utility function, using a discrete choice

\footnotetext{
${ }^{15}$ Wage prediction is needed for non-participants and is performed using the standard Heckman technique. Results are available upon request.

${ }^{16}$ This cost of childcare is computed according to the French Budget Survey 1994 (INSEE). In addition to the number and age of children, its amount depends on female labor supply. For instance, for children less than two years old, the annual cost of child care is 2,036 euros if the mother works 20 hours a week, 2,526 if she works 30 hours a week, 2,806 if she works 39 hours a week, and so on.
} 
model of labor supply. We assume that the utility derived by single individual $s$ for each choice $j=1, . . J$ of labor supply and for each subsequent level consumption is a random function:

$$
V^{s}\left(c_{j}^{s}, h_{j}^{s} ; \gamma^{s}\right)=U^{s}\left(c_{j}^{s}, h_{j}^{s} ; \gamma^{s}\right)+\varepsilon_{s j},
$$

where the deterministic part $U^{s}\left(c_{j}^{s}, h_{j}^{s} ; \gamma^{s}\right)$ is specified according to the quadratic form in (2), and where $\varepsilon_{s j}$ is a random term following an extreme value (I) distribution. The parameters can then be estimated using maximum likelihood technique according to the multinomial/conditional logit technique. Following common practice, we also allow the coefficients $\alpha_{10}^{s}$ and $\alpha_{20}^{s}$ to vary with observed heterogeneity (age, number of children and place of residence). In addition, we extend the multinomial logit specification so that preference parameters vary randomly over individuals rather than being fixed. Some of the parameters are then specified as $\alpha^{s}=\alpha+\sigma \gamma^{s}$ with $\gamma^{s}$ following a standard normal distribution. This allows for random taste heterogeneity and unrestricted substitution patterns between alternatives. A clear and comprehensive statement of this technique is Train (2002). Measurement errors due to the discretization are also accounted for in the way described by MaCurdy, Green and Paarch (1990). Results are reported in Table 4 in the Appendices.

\subsubsection{Predictions in case of divorce}

To compute the utility of divorce $U_{0}^{i}$, we need to allocate to each partner what would be her (his) labor supply if she (he) were on her (his) own. Let $h_{0}^{i}$ be the corresponding labor supply. We proceed as follows. We assume that expression (2), with $\alpha$ parameters obtained from single individuals, can be used to predict the behavior of individuals in couples in the case of divorce. To respect the stochastic nature of the random utility model described above, we generate 200 series of residuals $\varepsilon_{i j}(j=1, \ldots J)$ by drawing independently (across series and across hour choices) in an extreme value (I) distribution. For each series, we also draw a value of the unobserved heterogeneity $\gamma$ which assures that the 'divorced' individual respects usual regularity conditions for the optimal labor supply choice (monotonicity and strict quasiconcavity with respect to consumption and hours). The outside option $U_{0}^{i}$ then corresponds to the deterministic utility generated by the median optimal labor supply over the 200 draws, noted $h_{0}^{i}$. Post-reform optimal choices are defined in the same way, with retentions of the 200 sets of residuals generated in the first step.

Some general approximations must naturally be made to evaluate the outside options. In particular, we assume that children go systematically with the mother in case of a divorce. ${ }^{17} \mathrm{We}$ also predict the level of rent/mortgage repayment each spouse should pay, using an estimation conducted on demographic characteristics and assuming that the individuals remain in the same area as when married. ${ }^{18}$ This information is indeed necessary in the computation of household benefits. In the Appendices, Table 5 reports the distribution of labor supply for the 'unmarried'

\footnotetext{
${ }^{17}$ As a matter of fact, in France, children go with their mother nine times out of ten.

${ }^{18}$ These intermediary results are available upon request.
} 
state and the statistics of the distribution of preference parameters for threat points are shown in Tables 6 and 7.

\subsection{Calibrated preferences}

\subsubsection{Benchmark simulation}

For $i=f, m$ in a given household, we compute the preference parameters $\underline{\beta}^{i}$ using $\underline{\alpha}^{i}$ and a particular pair $\left(\underline{\Delta}^{f}, \underline{\Delta}^{m}\right)$ drawn in two independent normal distributions with zero mean and covariance matrices estimated on single individuals. We simultaneously draw combinations $\left(k^{f}, k^{m}\right)$ in $[0,1]$ uniform distributions. Among infinite possibilities, we choose for each household the first set of parameters which is consistent with observed behaviors and well-behaved preferences. More precisely, we select a draw for which (i) optimal choices $\left(h^{f}, h^{m}\right)$ obtained with program (1) match observed labor supplies, and (ii) the resulting set of preference parameters respects the conditions of strict quasi-concavity and strict monotonicity of the different utility functions.

We do not mean that resulting parameters $\underline{\beta}^{i}$ allocated to a given household are the 'true' ones nor that they are the only ones to meet the selection criteria. Simply, they correspond to plausible values which depart from the preferences of single individuals and are consistent with the Nash-bargaining hypothesis, the individual rationality and the observed labor supplies for individuals in couples. This constitutes our benchmark simulation - a consistent 'Nashbargaining world' - on which we can build a sensitivity analysis.

Notice that the Nash-bargaining solution considerably restricts the range of possible values for the draws. For a given set $\left(\underline{\alpha}^{i}, U_{0}^{i}\right)_{i=f, m}$ and a specific budget constraint, each draw of $(\Delta, k)$ parameters define one point on the Pareto frontier, hence one optimal allocation. Even for a large number of draws (up to 1 million), it is possible that in this set of points the allocation corresponding to observed labor supplies will never be found. In that case, the household is dropped. This is the case for $4.5 \%$ of the 2,898 households in our original sample. This explains the differences in Tables 8 and 9 in the final sample sizes between observed labor supply and simulated labor supply using calibrated parameters (see Appendices). On average, 37, 111 repetitive draws per household were necessary to meet all the conditions (min: 1 , for the lower 25\%: less than 121, for the upper 25\%: more than 10,459, max: 984,459).

Table 10 in the Appendices reports the marginal distributions of the calibrated degrees of caring $k^{f}$ and $k^{m}$. Albeit these two parameters are drawn independently from $[0,1]$ uniform distributions, a chi-square test on ranked values of $k^{f}$ and $k^{m}$ rejects their independence. Also, the marginal distribution of $k^{f}$ is right-skewed. The calibrated female degree of caring is particularly low $\left(k^{f} \leq 0.2\right)$ for almost $50 \%$ of the households.

With predicted outside options $U_{0}^{f}$ and $U_{0}^{m}$ and the benchmark draws for preferences, we can compute the surplus from cooperation/marriage. Figure 1 represents the distribution of the 


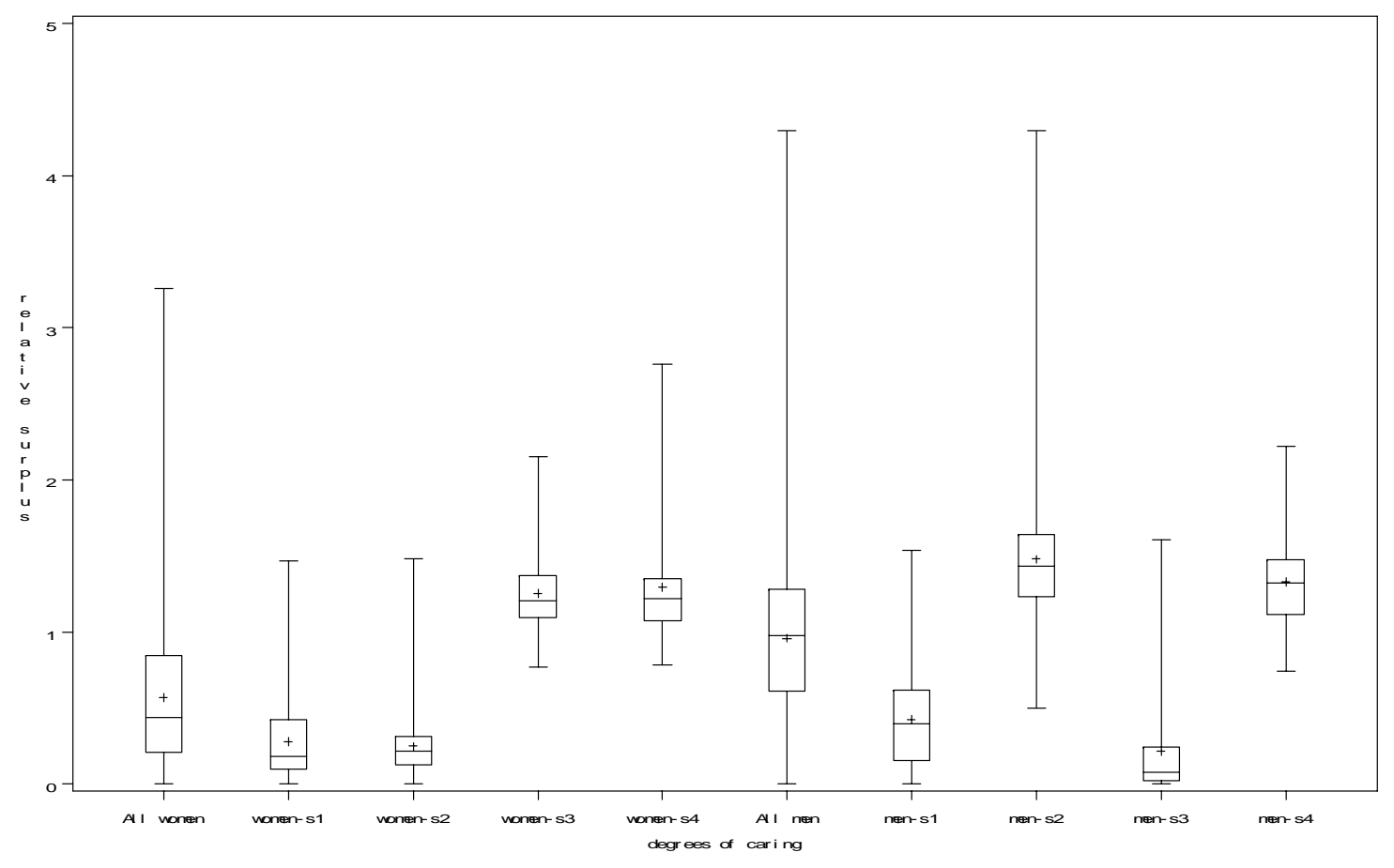

Figure 1: Distribution of relative surpluses, benchmark simulation

relative surplus $\frac{U^{i}-U_{0}^{i}}{U_{0}^{i}}$. The first five boxplots depict the distribution of wives' relative surplus. ${ }^{19}$ The first boxplot, labeled "All women", is computed on the whole sample of households, the second ("women-s1") on the sample of households with $\left(k^{f} \leq 0.2, k^{m} \leq 0.2\right)$, referred to as 'egoistic couples' in the following, the third on households with $\left(k^{f} \leq 0.2, k^{m} \geq 0.8\right)$, the fourth on households with $\left(k^{f} \geq 0.8, k^{m} \leq 0.2\right)$ and the fifth on households with $\left(k^{f} \geq 0.8\right.$, $k^{m} \geq 0.8$ ), referred to as 'alstruistic couples' in the following. The remaining boxplots refer to the distribution of husbands' relative surplus for the same combinations of caring. On average, the simulated surpluses are higher for men than for women, due to larger degrees of caring for men. As expected, egoistic individuals $\left(\right.$ i.e. $\left.k^{i} \leq 0.2\right)$ exhibit a smaller surplus.

\subsubsection{Alternative simulations}

We generate alternative simulations as follows. Previous calibrated values for $\beta$ parameters are transformed by $\pm 5,10,50$ or $100 \%$ variations, with unchanged calibrated values for $k^{f}$ and $k^{m}$. For a given magnitude of change, all combinations are considered (each $\beta$ parameter increased or decreased by $X \%$ ), which sums up to $2^{9}$ new possible vectors of $\beta$ s (i.e. $2^{10}$ without constraint (4)). Naturally, these alternative vectors of parameters must meet the regularity

\footnotetext{
${ }^{19}$ The length of the box represents the interquartile range. The marker in the box interior is the mean and the horizontal line the median. The vertical lines issuing from the box extend to the minimum and maximum values.
} 
conditions and be consistent with observed behaviors, i.e. lead to the maximisation of the Nash product for the observed labor supplies for both spouses. Table 11 in the Appendices reports the distribution of the number of alternative simulations by household. It can be seen, for instance, that when considering all $\pm 5 \%$ combinations on $\beta$ parameters, hence a small departure from the benchmark situation, at most 66 alternative vectors of parameters could be generated for $25 \%$ of the population and at least 164 alternative vectors for another $25 \%$ of the population.

As the magnitude of the variations increases, the number of households for which no alternative vector can be found increases. In particular, larger variations of the parameters more frequently lead to negative surpluses for the observed labor supplies (and to the rejection of the alternative set of parameters). It results that among remaining simulations, larger variations correspond to larger direct utilities on average. In the group of egoistic couples for instance, the average gain to cooperation represents $155 \%$ of the reservation utility in $\beta \pm 50 \%$ situations while only $36 \%$ in the $\beta \pm 5 \%$ situations.

\section{Household responses to variations in outside options}

\subsection{Exogenous shock on outside options}

We assess the impact on labor supply of exogenous changes in the threat points of women and men separately. We simulate relative variations of the reservation utilities from $-50 \%$ to $+50 \%$ with steps of $+1 \%$.

Primary remarks are required concerning the effect of the shocks on marriage. There are 35 combinations of labor supply available in principle. Yet, the number of choices is restricted by the fact that only some of them ensure that the cooperation surplus $W^{i}\left(c, h^{f}, h^{m}\right)-U_{0}^{i}$ remains positive for both spouses. An increase in the threat points yields smaller surpluses and the number of possible choices might even fall to zero (i.e. any choice leads the couple into divorce).

Naturally, these effects depend on the final specification of individual welfare indices since surpluses are all the smaller the more egoistic the spouses are. ${ }^{20}$ In the benchmark simulation for egoistic spouses, a 10\% (resp. 20\%) uniform increase of female threat points in the population leads $26 \%$ (resp. $52 \%$ ) of the households to divorce for any labor supply combination. Conversely, for altruistic spouses, almost all the households have 35 possible choices, even when female threat points increase by $50 \%$.

In alternative simulations, larger variations on $\beta s$ imply larger direct utilities - as mentioned above - hence smaller risk of divorce in case of a shock on the outside options. For instance, over the whole set of alternative simulations for egoistic spouses, a $50 \%$ increase in male threat points never leads to divorce in the $\beta \pm 100 \%$ case but implies divorce at least once for $23 \%$ of the households in the $\beta \pm 10 \%$ case.

\footnotetext{
${ }^{20}$ In the benchmark for egoistic spouses (resp. altruistic spouses), female welfare represents 1.18 (resp. 2.22) times the female reservation utility level at the median. Orders of magnitude are similar for men.
} 


\subsubsection{Labor supply responses with the benchmark simulation}

The following analysis is close to the idea of comparative statics, here with non-marginal changes in exogenous parameters (outside options) and in a framework which does not allow analytical solutions but necessarily requires simulations. Table 1 shows the result of the exercise for the whole population and different groups according to their degrees of caring. For instance, a uniform decrease of $1 \%$ of female outside options induces a change of labor supply for at least one of the two spouses - the household is a 'mover' - in $5 \%$ of the households overall and in $10 \%$ of the couples with egoistic wives (i.e. the $k^{f} \leq 0.2$ group).

Primarily, note that even small shocks yield labor supply changes in a non-negligible number of households, especially among egoistic couples. Interestingly, some regularities seem to appear. For negative shocks, the proportion of movers increases with the magnitude of the shock overall, as it does for each degree of caring. At the same time, for a given magnitude, the proportion of movers decreases with the level of caring of the spouse concerned by the shock. It is indeed rather intuitive to think that shocks will matter less in marriages with large initial surpluses from cooperation.

For positive shocks the trend is similar with some exceptions due to large shocks and egoistic spouses. In effect, large increases of the threat point are likely to (i) shrink the number of labor supply alternatives and consequently the probability of a move, (ii) reduce the number of couples for which cooperation holds. ${ }^{21}$ This is all the more true the more egoistic the spouse concerned by the shock is. For $k^{f} \leq 0.2$ (resp. $k^{m} \leq 0.2$ ), the proportion of movers declines when shocks are larger than $+20 \%$ (resp. $+30 \%){ }^{22}$

On the whole, the signs of the labor supply responses are in accordance with intuition. Detailed results are available upon request and we simply summarize the main aspects here. A decrease in the wife's threat point generally leads to a rise in her labor supply compared to her husband 's, and vice versa. When $U_{0}^{f}$ falls or $U_{0}^{m}$ increases, the most frequent reaction is a rise in female labor supply and a decrease in male labor supply. When $U_{0}^{f}$ rises or $U_{0}^{m}$ falls, most frequently, male labor supply increases while female activity remains constant. However, note that some spouses increase their labor supply when their threat point increases. For instance, take a $+10 \%$ change of the female threat point, which yields 463 movers for whom the median degrees of caring of women and men are 0.055 and 0.583 respectively. For 16 of the movers, it appears that the woman works more and the husband works less. In this sub-group, the median $k_{f}$ and $k_{m}$ are 0.408 and 0.108 respectively.

\footnotetext{
${ }^{21}$ Proportions in Table 1 refer to the number of movers - in the (smaller) group of post-shock cooperative couples - over the pre-shock number of cooperative couples. Note that policies aimed at 'saving marriage' should attempt to influence negatively rather than positively the outside options, then the situation of divorced ones!

${ }^{22}$ Note that for negative shocks the number of movers is larger when the shock concerns female outside options. This is not a general result, but simply caused by the fact that surpluses are on average larger for men than women. The same trend is observed for positive shocks, up to $+10 \%$, and the inverse beyond. Indeed, as male surplus is larger, a larger number of households remains cooperative after the shock, hence a large number of movers.
} 
The same is true when we consider the whole set of positive variations of female threat points. Overall, a small group emerges in which women work more. When comparing the median degrees of caring, this group turns out to be more altruistic than the rest of the cases. In addition, in this group some men also work more and are unequivocally more altrusitic (median $k_{m}$ of 0.571 compared to 0.073 in the rest of the group). ${ }^{23}$

Table 1: Proportion of movers according to the type of caring and the size and sign of the shock

\begin{tabular}{lccccccccccc}
\hline \hline & 1 & 2 & 3 & 4 & 5 & 10 & 20 & 30 & 40 & 50 & All \\
\hline$\Delta U_{0}^{f}<0$ and $\Delta U_{0}^{m}=0$ & & & & & & & & & & & \\
all couples & 5 & 9 & 12 & 15 & 18 & 28 & 39 & 45 & 49 & 52 & 27 \\
couples with $k^{f} \leq 0.2$ & 10 & 17 & 22 & 28 & 32 & 50 & 67 & 74 & 79 & 82 & 46 \\
couples with $0.2<k^{f} \leq 0.4$ & 1 & 3 & 5 & 6 & 9 & 14 & 23 & 27 & 33 & 40 & 16 \\
couples with $0.4<k^{f} \leq 0.6$ & 0.3 & 1 & 2 & 3 & 3 & 5 & 10 & 14 & 17 & 21 & 8 \\
couples with $0.6<k^{f} \leq 0.8$ & 0.3 & 0.7 & 1 & 1 & 2 & 4 & 7 & 8 & 12 & 13 & 5 \\
couples with $k^{f}>0.8$ & 0 & 0.4 & 0.4 & 1 & 1 & 2 & 3 & 5 & 7 & 8 & 3 \\
\hline$\Delta U_{0}^{f}>0$ and $\Delta U_{0}^{m}=0$ & & & & & & & & & & & \\
all couples & 2 & 4 & 6 & 9 & 11 & 17 & 19 & 18 & 14 & 14 & 11 \\
couples with $k^{f} \leq 0.2$ & 4 & 8 & 12 & 16 & 20 & 29 & 29 & 18 & 9 & 5 & 15 \\
couples with $0.2<k^{f} \leq 0.4$ & 1 & 1 & 2 & 3 & 3 & 8 & 18 & 29 & 28 & 25 & 12 \\
couples with $0.4<k^{f} \leq 0.6$ & 0.3 & 1 & 2 & 2 & 2 & 4 & 9 & 14 & 20 & 27 & 8 \\
couples with $0.6<k^{f} \leq 0.8$ & 0 & 0 & 0.3 & 1 & 1 & 2 & 8 & 12 & 17 & 20 & 6 \\
couples with $k^{f}>0.8$ & 0 & 0.7 & 0.7 & 1 & 1 & 2 & 4 & 7 & 9 & 12 & 4 \\
\hline$\Delta U_{0}^{m}<0$ and $\Delta U_{0}^{f}=0$ & & & & & & & & & & & \\
all couples & 2 & 5 & 6 & 7 & 8 & 12 & 17 & 21 & 24 & 26 & 13 \\
couples with $k^{m} \leq 0.2$ & 10 & 21 & 26 & 31 & 36 & 48 & 59 & 66 & 68 & 69 & 44 \\
couples with $0.2<k^{m} \leq 0.4$ & 1 & 2 & 4 & 6 & 6 & 11 & 18 & 24 & 29 & 32 & 13 \\
couples with $0.4<k^{m} \leq 0.6$ & 0.9 & 1.5 & 2 & 2 & 3 & 5 & 9 & 13 & 17 & 20 & 7 \\
couples with $0.6<k^{m} \leq 0.8$ & 0.6 & 1 & 1 & 2 & 2 & 3 & 6 & 10 & 12 & 14 & 5 \\
couples with $k^{m}>0.8$ & 0.5 & 0.8 & 1 & 1 & 2 & 2 & 5 & 8 & 9 & 11 & 4 \\
\hline$\Delta U_{0}^{m}>0$ and $\Delta U_{0}^{f}=0$ & & & & & & & & & & & \\
all couples & 1 & 3 & 4 & 6 & 7 & 13 & 21 & 29 & 35 & 38 & 16 \\
couples with $k^{m} \leq 0.2$ & 2 & 5 & 9 & 10 & 13 & 18 & 22 & 25 & 19 & 15 & 14 \\
couples with $0.2<k^{m} \leq 0.4$ & 2 & 4 & 5 & 8 & 9 & 21 & 37 & 49 & 53 & 47 & 23 \\
couples with $0.4<k^{m} \leq 0.6$ & 1 & 3 & 4 & 5 & 7 & 12 & 23 & 36 & 45 & 53 & 19 \\
couples with $0.6<k^{m} \leq 0.8$ & 0.6 & 1 & 4 & 5 & 6 & 11 & 19 & 26 & 33 & 40 & 15 \\
couples with $k^{m}>0.8$ & 0.8 & 1 & 2 & 2 & 3 & 6 & 11 & 19 & 27 & 32 & 10 \\
\hline
\end{tabular}

Note: all figures are percentages; the first row indicates the absolute percentage increase of the threat point; the first column tells us which spouse is affected and the sign of this shock; the core of the table represents the proportion of movers for the whole population and for each caring configuration.

\footnotetext{
${ }^{23}$ Such altruistic behaviors are found in several studies, for instance in Chiappori et al. (2002) as the authors show that a positive shock on female wages benefits mostly to the husbands as wives behave altruistically. This yields an income effect on male labor supply.
} 


\subsubsection{Labor supply responses with alternative simulations}

The previous exercise is repeated on the alternative vectors of parameters. For the sake of brevity, we only report the results concerning a shock on female outside options. ${ }^{24}$ Table 2 reports the percentages of movers for different variations of the threat point, for different orders of magnitude of the parameter changes and for given definitions of the number of movers.

Not surprisingly, any prediction on the number of movers is highly sensitive to the simulated values of preference parameters. For a given couple, it is often possible to find one alternative vector of $\beta s$ for which the couple will react to the shock, as shown in Table 2 by the first rows for each parameter variation. For instance, with the $\beta \pm 10 \%$ variation and for a $+10 \%$ increase of $U_{0}^{f}$, it follows that $78 \%$ of the households move at least once over the whole set of alternative parameter vectors.

Therefore, we establish two simple rules to rationalize the results, keeping in mind that the number of alternative vectors differs across households (see Table 11 in the Appendices). With the first rule, referred to as the 'discrete movers' rule, a couple is considered as a mover if a move occurs in more than half of the alternative simulations. ${ }^{25}$ With the second, referred to as the 'frequency of moves' rule, we attribute to each household a frequency corresponding to the number of moves occuring over the whole set of alternative simulations for this household, then compute an aggregate mean of moves over all the households.

Results are also reported in the second and third rows for each parameter variation in Table 2. Let us come back to the previous example with a $\beta \pm 10 \%$ variation and for a $+10 \%$ increase of $U_{0}^{f}$. In that case, the proportion of movers represents only $14 \%$ of the population according to the 'discrete movers' rule and $20 \%$ with the 'frequency of move' rule. These figures can be somewhat compared to the $17 \%$ of movers in the benchmark simulation (' $10 \%$ ' column and $6^{\text {th }}$ row of Table 1).

Reading Table 2 vertically, it turns out that larger variations of the $\beta s$ yield less household reactions to the distribution effect. For instance, according to the 'discrete movers' rule, a $-10 \%$ change of $U_{0}^{f}$ leads to $18 \%$ of movers for $\beta \pm 5 \%$, only to $6 \%$ for $\beta \pm 50 \% .{ }^{26}$ In effect, as commented earlier, larger variations of the parameters imply larger gains to marriage so that shocks on the threat point matter less.

More detailed results depending on caring are not reported in Table 2 but are worth mentionning here: similarly to the benchmark situation, a shock is more likely to produce labor supply variations when the wife is egoistic; again, the most frequent reaction is a decrease in female labor supply relative to her partner's when her threat point rises and an increase otherwise.

\footnotetext{
${ }^{24}$ Similar conclusions can be drawn for male threat points. Results are available upon request.

${ }^{25}$ More generally, it is possible to define a 'discrete movers $X \%$ ' in which a couple is considered as a mover if it moves in more than $X \%$ of the alternative simulations. 'Discrete movers $10 \%$ ' and 'discrete movers $25 \%$ ' are available upon request.

${ }^{26}$ This is true overall, and independently for each group according to the level of caring.
} 
Table 2: Alternative simulations: percentage of movers

\begin{tabular}{lcccccc}
\hline \hline & \multicolumn{6}{c}{ Variations of female outside options } \\
& $-10 \%$ & $-5 \%$ & $-1 \%$ & $1 \%$ & $5 \%$ & $10 \%$ \\
\hline$\beta \pm 5 \%$ & $83 \%$ & $77 \%$ & $57 \%$ & $53 \%$ & $78 \%$ & $85 \%$ \\
'discrete movers' rule & $18 \%$ & $6 \%$ & $0 \%$ & $0 \%$ & $5 \%$ & $18 \%$ \\
'frequency of move' rule & $22 \%$ & $13 \%$ & $3 \%$ & $2 \%$ & $12 \%$ & $24 \%$ \\
$\beta \pm 10 \%$ & $79 \%$ & $71 \%$ & $43 \%$ & $38 \%$ & $67 \%$ & $78 \%$ \\
'discrete movers' rule & $16 \%$ & $5 \%$ & $0 \%$ & $0 \%$ & $3 \%$ & $14 \%$ \\
'frequency of move' rule & $22 \%$ & $13 \%$ & $3 \%$ & $2 \%$ & $10 \%$ & $20 \%$ \\
$\beta \pm 50 \%$ & $24 \%$ & $16 \%$ & $4 \%$ & $2.5 \%$ & $13.5 \%$ & $25 \%$ \\
'discrete movers' rule & $6 \%$ & $3 \%$ & $1 \%$ & $0 \%$ & $2 \%$ & $6 \%$ \\
'frequency of move' rule & $7 \%$ & $4 \%$ & $1 \%$ & $1 \%$ & $3 \%$ & $7 \%$ \\
$\beta \pm 100 \%$ & $8 \%$ & $4 \%$ & $0.7 \%$ & $0 \%$ & $2.6 \%$ & $5.4 \%$ \\
'discrete movers' rule & $4 \%$ & $2 \%$ & $0 \%$ & $0 \%$ & $1 \%$ & $2 \%$ \\
'frequency of move' rule & $4 \%$ & $2 \%$ & $0 \%$ & $0 \%$ & $1 \%$ & $2 \%$ \\
\hline
\end{tabular}

Note : for each variation of the betas, the first row corresponds to the proportion of households which move at least once over the whole set of alternative beta vectors; the second and third rows correspond to the number of movers according to the rules described in the text.

\section{Tax-benefit reform and threat point variations}

The reform corresponds to an increase in child benefit for single individuals, positively related to the work duration. The idea is to decrease the costs of work for lone parents (and notably the purchase of childcare). The actual level of benefits is increased by $100 \%$ in case of inactivity, by $120 \%$ for part-time workers (between 20 and 30 hours) and by $140 \%$ in case of full-time activity (39 hours and over).

This reform implies substantial financial gains for actual single parents compared to the present situation. This is also the case for married mothers in case of divorce, as described in Table 3. The reform thus represents a pure distribution effect for couples, interestingly driven by tax-benefit rules for single individuals.

Table 3: Consumption variation for mothers in case of divorce

\begin{tabular}{llllll}
\hline \hline & $h^{f}=0$ & $h^{f}=20$ & $h^{f}=30$ & $h^{f}=39$ & $h^{f}=45$ \\
\hline $10 \%$ & 9.97 & 9.85 & 7.88 & 7.87 & 7.18 \\
$50 \%$ & 15.09 & 16.55 & 13.41 & 13.47 & 12.58 \\
$90 \%$ & 26.64 & 28.09 & 24.15 & 25.13 & 23.78 \\
\hline
\end{tabular}

Note : for $50 \%$ of the women, the level of consumption at the outside option increases by $13.41 \%$ when working 30 hours weekly. 
We simulate the impact of the reform on outside options of married women. Despite large consumption gains, the reservation utility increases only by $1.05 \%$ on average over the 1,208 women concerned by the reform, by $3.31 \%$ at most and $0.01 \%$ at least. As a result, the effects of the reform on labor supply are rather modest. For the benchmark simulation, $2.5 \%$ of the couples react to this reform. The order of magnitude of the results is consistent with previous findings since a $1 \%$ uniform increase in female outside options generates $2 \%$ of movers in Table 1 .

As noted before, the number of movers in couples is heavily dependent on the calibrated parameters. For $46 \%$ (resp. 32\%) of the households, it is possible to find at least one set of parameters $\beta \pm 5 \%$ (resp. $\beta \pm 50 \%, \beta \pm 100 \%$ ) for which households display a labor supply response. However, using the two 'averaging' measures suggested previously, we find that the number of movers is $0.2 \%$ (resp. $0.3 \%, 0.1 \%$ ) according to the 'discrete movers' rule and $2.3 \%$ (resp. $0.5 \%, 0.1 \%$ ) according to the 'frequency of moves' rule. Again, these figures are consistent with previous simulations and can be compared to the ' $1 \%$ ' column of Table 2 for the appropriate alternative (in particular for $\beta \pm 5 \%$, the orders of magnitude 46, 0.2 and 2.3 above compare well to 53, 0 and 2 in Table 2). Finally note that the most frequent reaction is a decrease in female labor supply relative to her partner's.

\section{Conclusion}

This paper consists of an original exercise to study some of the implications of the Nashbargaining model on household labor supply with taxation. In particular, we gauge the possible effects on labor supply resulting from shocks on spouses' external outside options, including the pure distribution effect coming from a realistic reform of the child benefits for lone parents.

The contribution remains modest, while it constitutes one of the very first attempts to implement a cooperative model of labor supply with taxation and participation decisions. The calibration technique presented here has been designed to fit the Nash-bargaining model with observed behaviors. Future research should rely on estimations, even if many other hypotheses must be made on preferences in that case. In particular, simple functional forms must often be chosen for convenience rather than realism and are hardly supported by empirical arguments. On the other hand, necessary cardinalization assumptions - inherent to the Nash-bargaining solution - are addressed very generally here and the calibration strategy allows both flexible functional forms and preferences in couples which depart from those when single in several ways.

Moreover, the results from our simulations seem to hold throughout an extensive sensitivity analysis on the calibrated preference parameters. Firstly, it turns out that the effects on labor supply stemming from variations in the outside option necessarily depend on the level of altruism in the household. Only egoistic spouses seem to respond substantially to these shocks. Secondly, it could be the case that preferences change throughout marriage. Preference parameters may 
depart from the values when single in such a way that direct utility increases, which we can consider as a higher cardinalization due to the increased happiness from marriage. Conversely, if preferences come closer to the singles' values, the gain from cooperation can decrease down to zero. Thirdly, it seems that important variations in fall back situations - when taken as divorce - are required in order to dramatically change the levels of labor supply, while such variations do not seem achievable by the suggested reform.

Many improvements are naturally required. In particular, it seems that this branch of research - due to its intrinsic cardinal nature - should ultimately resort to richer data than those which can be derived from the observation of demand behavior, as suggested by Van Praag (1994).

\section{References}

[1] Apps, P.F. and R. Rees (1999): "On the taxation of trade within and between households". Journal of Public Economics, 73, 241-263.

[2] Ashworth J. and D. T. Ulph (1981): "Households Models", in C.V. Brown (eds.), Taxation and Labour Supply, London, Allen and Unwin.

[3] Bargain, O. and I. Terraz (2003): "Evaluation et mise en perspective des effets incitatifs et redistributifs de la Prime pour l'Emploi.", Economie et Prévision, 160/161, 121-149.

[4] Bargain, O. et N. Moreau (2004): "Effets d'une réforme fiscale sur l'offre de travail des ménagesdans un cadre collectifsimulé", forthcoming in Actualité Economique.

[5] Barmby T. (1994): "Household Labour Supply: Some notes on Estimating a Model with Pareto Optimal Outcomes", Journal of Human Resources, 29, 932-940.

[6] Barmby T. (1996): "Computation of Nash-Bargained Models of Household Labour Supply", Bulletin of Economic Research, 48, 161-165.

[7] Barmby, T. and N. Smith (2001): "Household Labor Supply in Britain and Denmark: Some Interpretation Using a Model of Pareto Optimal Behavior", Applied Economics, 33, 1109-1116.

[8] Blundell, R.W. , P.-A. Chiappori, T. Magnac and C. Meghir (2001): "Collective Labor Supply: Heterogeneity and Nonparticipation", mimeo, University College London.

[9] Browning M. (1992): "Children and Household Economic behavior", Journal of Economic Literature, 30, 1434-1475.

[10] Browning M. and V. Lechene (2001): "Caring and Sharing: Tests Between Alternative Models of Intra-household Allocation", Working Paper, Oxford University. 
[11] Chen Z. and F. Woolley (2001): "A Cournot-Nash Model of Family Decision Making", The Economic Journal, 111, 722-748.

[12] Chiappori, P.-A. (1988a): "Rational Household Labor Supply", Econometrica, 56, 63-89.

[13] Chiappori, P.-A. (1988b): "Nash-bargained households decisions: a comment", International Economic Review, 29, 4, 791-797.

[14] Chiappori, P.-A. (1991): "Nash-bargained households decisions: a rejoinder", International Economic Review, 32, 3, 761-762.

[15] Chiappori, P.-A. (1992): "Collective Labor Supply and Welfare", Journal of Political Economy, 100, 437-467.

[16] Chiappori, P.-A., B. Fortin and G. Lacroix (2002): "Marriage Market, Divorce Legislation and Household Labor Supply", Journal of Political Economy, 110, 37-72.

[17] Chiappori, P.-A. , R.W. Blundell and C. Meghir (2002): "Collective Labor Supply with Children", IFS working paper, W02/08.

[18] Chiappori, P.-A. and O. Donni (2003): "Is Nash-bargaining testable", mimeo.

[19] Chiappori, P.-A. and O. Donni (2004): "Les modèles non-unitaires de comportement du ménage: un survol de la littérature", forthcoming in Actualité Economique.

[20] Del Boca, D. and C. Flinn (2004): "Modes of Sousal Interaction and the Labor Market Environment", NYU working paper.

[21] Donni, O. (2000): "Essais sur les modèles collectifs de comportement du ménage", PhD thesis, EHESS.

[22] Donni, O. (2004): "Labor supply, Home Production and Welfare Comparisonz", working paper, University of Cergy-Ponthoise.

[23] Fortin, B. and G. Lacroix (1997): "A Test of the Neo-Classical and Collective Models of Household labor Supply", Economic Journal, 107, 933-955.

[24] Gonzàlez, L. (2004): "The Effect of Benefits on Single Motherhood in Europe", working paper, Universitat Pompeu Fabra.

[25] Haddad L. and Kanbur R. (1994): "Are better off households more unequal or less unequal", Oxford Economic Papers, 46, 445-458.

[26] Konrad K. A. and Lommerud K. E (2000): "The bargaining family revisited", Canadian Journal of Economics, 33, 471-487. 
[27] Kooreman, P. and A. Kapteyn (1990): "On the Implementation of Some Game Theoretic Models of Labor Supply", Journal of Human Resources, 25, 584-598

[28] Laisney, F. (2002) (editor): "Welfare Analysis of Fiscal and Social Security Reforms in Europe: Does the Representation of the Family Decision Process Matter?" Final Report on EU-project VS/2000/0778, Mannheim, ZEW.

[29] Lundberg S.J and Pollak R. A. (1993): "Separate spheres bargaining and the marriage market", Journal of Political Economy, 101, 988-1010.

[30] Lundberg S.J. and R.A. Pollak (1996): "Bargaining and Distribution in Marriage", Journal of Economic Perspectives, 10, 139-158.

[31] MaCurdy, T., D. Green and H. Paarsch (1990): "Assessing Empirical Approaches for Analysing Taxes and Labor Supply", Journal of Human Resources, 25, 415-490.

[32] Manser M. and M. Brown (1980): "Marriage and Household Decision-making: A Bargaining Analysis", International Economic Review, 21, 31-44.

[33] McElroy M.B. and Horney M. J (1981): "Nash-bargained household decisions: toward a Generalization of the Theory of Demand", International Economic Review, 22, 333-349.

[34] McElroy M.B. and Horney M. J (1990): "Nash-bargained household decisions: reply", International Economic Review, 31, 237-240.

[35] McElroy M.B. (1990): "The empirical content of Nash-bargained household behavior", Journal of Human Resources, 25, 559-583.

[36] Moreau, N. and O. Donni (2002): "Une estimation d'un modèle collectif d'offre de travail avec taxation", Annales d'Economie et de Statistiques, 62, 55-83.

[37] Ransom M. R. (1987): "An Empirical Model of Discrete and Continuous Choice in Family Labor Supply", The Review of Economics and Statistics, 3, 465-472.

[38] Rubalcava, L. and D. Thomas (2000): "Family bargaining and welfare", mimeo RAND, UCLA.

[39] Stern N. (1986): "On The Specification of Labor Supply Functions", in R. Blundell and I. Walker (eds.), Unemployment, Search and Labour Supply, Cambridge University Press, 143-189

[40] Train K. (2002): Discrete Choice Methods with Simulation, Cambridge University Press.

[41] Van Praag, B. (1994): "Ordinal and cardinal utility: an integration of the two dimensions of the welfare concept", in The Measurment of Household Welfare, Blundell, Preston and Walker eds., 86-110 
[42] Vermeulen, F. (2002): "Collective household models: principles and main results", Journal of Economic Surveys, 16 (4), 533-564.

[43] Vermeulen, F. (2004): "A collective model for female labour supply with nonparticipation and taxation", forthcoming in Journal of Population Economics. 


\section{Appendices}

\subsection{Data and microsimulation}

The data are taken from the French Household Budget Survey 1994 and monetary variables have been grossed up to 1998, assuming the demography constant (see Bargain and Terraz, 2003). The dataset contains information for 28,973 individuals living in 11, 220 households.

We select a sample of married and cohabiting couples and two samples of single individuals (men and women). In each case, we keep households where the adults are aged between 25 and 64 and available for the labor market, i.e. not disabled, retired or in education. Households with self-employed workers or farmers are also excluded since their labor supply behavior may be rather different from salary workers; also, independent workers are subject to income tax rules which are substantially different from the ones applied to salary income and which require additional information not available here.

Employees not reporting important pieces of information (e.g. number of working hours) are excluded from each sample. To further increase data homogeneity, 'extreme households' are selected out, notably those receiving important amounts of non-labor income; with more than 3 children; whose children earn substantial labor income. Households with more than two decision-makers (i.e. other adults than the basic couple) are also discarded. Descriptive statistics are available upon request and distribution of hours are shown in Figures ??, where the vertical axis represents frequencies (percentages) and the horizontal axis weekly working hours.

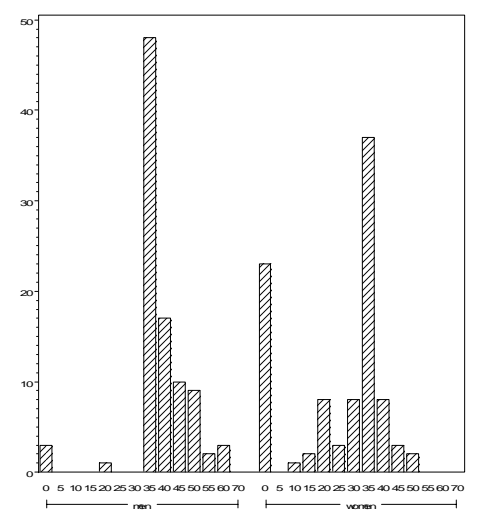

Couples' weekly labor supply (French family budget survey, year 1994)

\subsection{Estimation on single individuals}

Unobserved heterogeneity appears to be significant for the consumption term $\left(\alpha_{10}^{s}\right)$ and the leisure term $\left(\alpha_{20}^{s}\right)$ for single women and for both the interaction term and the consumption 
quadratic term for single men $\left(\alpha_{12}^{s}\right.$ and $\left.\alpha_{11}^{s}\right)$. All coefficients are statistically different from 0 at conventional levels, except for the Paris region in women's consumption term and in men's leisure term. All else being equal, leisure and consumption interact positively on single men's level of utility, unlike single women's. A similar difference arises for $c^{2}$. According to the estimates, having children has a negative effect on single women's labor supply and a negative effect for single men.

Table 4: Mixed logit estimates for single individuals

\begin{tabular}{|c|c|c|}
\hline Variable & coef. single women & coef. single men \\
\hline$c$ & $0.105(0.037)$ & $-0.164(0.039)$ \\
\hline$c \times($ age $/ 40)$ & $0.048(0.016)$ & $0.052(0.019)$ \\
\hline$(c \times$ paris $)$ & $-0.007(0.007)$ & $0.024(0.009)$ \\
\hline$c \times k i d s$ & $0.011(0.004)$ & $-0.032(0.011)$ \\
\hline$l$ & $0.658(0.260)$ & $0.706(0.111)$ \\
\hline$l \times($ age $/ 40)$ & $0.148(0.039)$ & $0.199(0.037)$ \\
\hline$l \times$ paris & $-0.052(0.019)$ & $0.032(0.021)$ \\
\hline$l \times k i d s$ & $0.037(0.010)$ & $-0.101(0.036)$ \\
\hline$c \times l$ & $-0.0007(0.0002)$ & $0.001(0.0003)$ \\
\hline$c^{2}$ & $-1.572(0.377)$ & $0.680(0.253)$ \\
\hline$l^{2}$ & $-0.003(0.001)$ & $-0.004(0.0004)$ \\
\hline \multicolumn{3}{|c|}{ Unobserved heterogeneity on $c$ : } \\
\hline$\sigma_{c}$ & $0.013(0.008)$ & $/$ \\
\hline \multicolumn{3}{|c|}{ Unobserved heterogeneity on $l$ : } \\
\hline$\sigma_{l}$ & $0.067(0.023)$ & / \\
\hline \multicolumn{3}{|c|}{ Unobserved heterogeneity on $c \times l$ : } \\
\hline$\sigma_{c l}$ & / & $3.014(0.522)$ \\
\hline \multicolumn{3}{|c|}{ Unobserved heterogeneity on $c^{2}$ : } \\
\hline$\sigma_{c^{2}}$ & $/$ & $0.246(0.119)$ \\
\hline \multicolumn{3}{|l|}{ Measurement error: } \\
\hline$\sigma_{\varepsilon}$ & $0.105(0.002)$ & $0.087(0.003)$ \\
\hline number of observations & 732 & 502 \\
\hline
\end{tabular}

Notes : leisure is $l=T-h$. Paris region equals 1 if the couple lives in the Paris region, 0 otherwise. Standard errors are given in brackets. For women, $c$ is divided by $10^{3}, c^{2}$ by $10^{10}$ and $\sigma_{c}$ by $10^{3}$. For men, $c$ is divided by $10^{3}, c^{2}$ by $10^{10}, \sigma_{c l}$ by $10^{7}$ and $\sigma_{c^{2}}$ by $10^{10}$. 


\subsection{Results of the calibration}

Table 5: Threatpoints: simulated distribution of labor supplies

\begin{tabular}{lccccccc}
\hline \hline Weekly labor supply & 0 & 20 & 30 & 39 & 45 & 55 & 55 \\
\hline Married men & $0 \%$ & $0.29 \%$ & $2.42 \%$ & $57.55 \%$ & $4.37 \%$ & $19.00 \%$ & $16.37 \%$ \\
Married women & $0.51 \%$ & $0.87 \%$ & $29.84 \%$ & $68.64 \%$ & $0.14 \%$ & $\nearrow$ & $\nearrow$ \\
\hline
\end{tabular}

Table 6: Distribution of preference parameters - women

\begin{tabular}{ccccccccccc}
\hline \hline \multicolumn{1}{c}{ threat point } & \multicolumn{1}{c}{ individual utility } \\
& $\widetilde{\alpha}_{10}^{f}$ & $\widetilde{\alpha}_{20}^{f}$ & $\widetilde{\alpha}_{12}^{f}$ & $\widetilde{\alpha}_{11}^{f}$ & $\widetilde{\alpha}_{22}^{f}$ & $\widetilde{\beta}_{10}^{f}$ & $\widetilde{\beta}_{20}^{f}$ & $\widetilde{\beta}_{12}^{f}$ & $\widetilde{\beta}_{11}^{f}$ & $\widetilde{\beta}_{22}^{f}$ \\
$10 \%$ & 1.65 & 1.00 & -.82 & -1.86 & -3.34 & 1.29 & 1.00 & -.74 & -2.33 & -.3 .28 \\
$50 \%$ & 1.89 & 1.00 & -.78 & -1.77 & -3.17 & 1.72 & 1.00 & -.46 & -1.82 & -3.08 \\
$90 \%$ & 2.14 & 1.00 & -.73 & -1.65 & -2.95 & 2.16 & 1.00 & .72 & -1.31 & -2.80 \\
\hline
\end{tabular}

Notes: For $50 \%$ of the women in couples, $\widetilde{\alpha}_{10}^{f}$ is equal to 1.89 and $\widetilde{\beta}_{11}^{f}$ to -1.82 . For $10 \%$ of them, $\widetilde{\beta}_{22}^{f}$ is less than -3.28 . The parameters $\widetilde{\alpha}_{10}^{f}$ and $\widetilde{\beta}_{10}^{f}$ have been multiplied by $10^{4}, \widetilde{\alpha}_{12}^{f}$ and $\widetilde{\beta}_{12}^{f}$ by $10^{6}, \widetilde{\alpha}_{11}^{f}$ and $\widetilde{\beta}_{11}^{f}$ by $10^{10}$ and $\widetilde{\alpha}_{22}^{f}$ and $\widetilde{\beta}_{22}^{f}$ by $10^{3}$.

Table 7: Distribution of preference parameters - men

\begin{tabular}{|c|c|c|c|c|c|c|c|c|c|c|}
\hline & \multicolumn{5}{|c|}{ threat point } & \multicolumn{5}{|c|}{ individual utility } \\
\hline & $\widetilde{\alpha}_{10}^{m}$ & $\widetilde{\alpha}_{20}^{m}$ & $\widetilde{\alpha}_{12}^{m}$ & $\widetilde{\alpha}_{11}^{m}$ & $\widetilde{\alpha}_{22}^{m}$ & $\widetilde{\beta}_{10}^{m}$ & $\widetilde{\beta}_{20}^{m}$ & $\widetilde{\beta}_{12}^{m}$ & $\widetilde{\beta}_{11}^{m}$ & $\widetilde{\beta}_{22}^{m}$ \\
\hline $10 \%$ & -2.22 & 1.00 & 1.15 & 3.22 & -4.17 & 0.48 & 1.00 & 0.56 & -9.95 & -4.77 \\
\hline $50 \%$ & -1.76 & 1.00 & 1.54 & 6.33 & -3.92 & 1.52 & 1.00 & 1.32 & -6.35 & -4.00 \\
\hline $90 \%$ & -1.08 & 1.00 & 1.95 & 9.85 & -3.69 & 2.78 & 1.00 & 2.17 & -3.17 & -3.46 \\
\hline
\end{tabular}


Table 8: Married women: simulated versus observed labor supply

\begin{tabular}{lcc}
\hline \hline Weekly labor supply & observed & simulated \\
\hline 0 & $25.57 \%$ & $22.51 \%$ \\
20 & $11.28 \%$ & $11.63 \%$ \\
30 & $13.35 \%$ & $13.95 \%$ \\
39 & $42.79 \%$ & $44.69 \%$ \\
45 & $7 \%$ & $7.23 \%$ \\
\hline no. of observations & 2898 & 2768 \\
\hline
\end{tabular}

Table 9: Married men: simulated versus observed labor supply

\begin{tabular}{lcc}
\hline \hline Weekly labor supply & observed & simulated \\
\hline 0 & $3.17 \%$ & $2.13 \%$ \\
20 & $1.73 \%$ & $1.70 \%$ \\
30 & $3.45 \%$ & $3.47 \%$ \\
39 & $57.25 \%$ & $57.77 \%$ \\
45 & $16.08 \%$ & $14.81 \%$ \\
50 & $10.11 \%$ & $12.07 \%$ \\
55 & $8.21 \%$ & $8.06 \%$ \\
\hline no. of observations & 2898 & 2768 \\
\hline
\end{tabular}


Table 10: Marginal distributions of the calibrated degrees of caring

\begin{tabular}{lcc}
\hline \hline & calibrated $k^{m}$ & calibrated $k^{f}$ \\
\hline$\leq 0.1$ & 9.68 & 36.09 \\
] $0.1 ; 0.2]$ & 6.50 & 13.15 \\
] $0.2 ; 0.3]$ & 7.51 & 9.65 \\
] $0.3 ; 0.4]$ & 7.44 & 7.12 \\
] $0.4 ; 0.5]$ & 9.32 & 7.01 \\
] $0.5 ; 0.6]$ & 10.30 & 6.29 \\
] $0.6 ; 0.7]$ & 11.99 & 5.27 \\
] $0.7 ; 0.8]$ & 10.77 & 5.27 \\
] $0.8 ; 0.9]$ & 13.22 & 5.17 \\
$\geq 0.9$ & 13.26 & 4.99 \\
\hline Total & 100 & 100
\end{tabular}

Note: all figures are percentages.

Table 11: Distribution of the number of alternative simulations per household

\begin{tabular}{lcccccc}
\hline \hline & Number of households & $10 \%$ & $25 \%$ & $50 \%$ & $75 \%$ & $90 \%$ \\
\hline$\beta \pm 5 \%$ & 2731 & 39 & 66 & 104 & 164 & 246 \\
$\beta \pm 10 \%$ & 2704 & 12 & 21 & 38 & 71 & 136 \\
$\beta \pm 50 \%$ & 2621 & 1 & 1 & 3 & 8 & 24 \\
$\beta \pm 100 \%$ & 2020 & 1 & 1 & 1 & 3 & 10 \\
\hline
\end{tabular}

